\title{
Managing Forest Road Removal Using Dynamic Programming: A Pilot Study
}

\author{
Rebecca L. Teasley \\ Environmental Resources Engineering \\ Humboldt State University \\ Arcata, California 95521 USA
}

Received May 1, 2002

Accepted June 15, 2002

\begin{abstract}
Since the late 1970's the U.S. Geologic Survey (USGS) has led a program to remove abandoned logging roads in Redwood National Park. Because abandoned logging roads contribute large amounts of sediment to local fish bearing streams, the ecosystem health of these waterways suffer. Recent research has identified the effectiveness of preventing sediment from reaching the streams for different road treatments after significant storm events. However, road removal is expensive and time consuming. This research reported in this paper was part of that pilot study, and specifically reviews the feasibility of the optimization algorithm Dynamic Programming (DP), using data from recent research on road removal effectiveness. The DP sought to determine the road removal treatment that maximizes the amount of sediment saved from erosion, while meeting a budgetary constraint. The results indicate that DP is an effective tool for developing a road removal management plan. However, the order in which roads and stream crossings are treated has a large effect on the solution, indicating that the DP formulation has room for improvement. The USGS is supporting further research to reformulate the DP.
\end{abstract}

\section{INTRODUCTION}

Old logging roads often create highly erosive conditions, which impair the ecological health of streams and rivers. Redwood National Park, located in north coastal California, contains a network of old logging roads. Most of these roads are abandoned and contribute large volumes of sediment to fish-bearing creeks, which impair stream health. Since 1978, the U.S. Geological Survey (USGS) has led a program to remove and restore the abandoned roads to natural conditions. The challenge in the program is to 1) determine which roads to treat, and 2) to determine the optimal level of treatment. The objective of this pilot study is to determine if the optimization algorithm Dynamic Programming is an effective tool for developing a forest logging road removal management plan.
II. PROJECT BACKGROUND

Logging roads were commonly constructed across the steep, forested landscape of southwest Canada and the Pacific Northwest of the United States; many are now abandoned and unmaintained [1]. While these unmaintained roads contribute major sediment problems, few studies have evaluated changes in sediment yields as the roads are either abandoned, or obliterated and restored.

An opportunity to study sediment yields from abandoned and restored roads presented itself at Redwood National Park. Redwood National Park scientists and engineers are experts in road restoration at a watershed scale; they have developed, tested, and applied road-restoration techniques at a scale virtually unprecedented throughout the world [2]. Since Redwood National Park was expanded in 1978, 134 of 
300 road miles have been restored or obliterated within the park boundaries. This work has moved about $1,300,000$ cubic yards of material [2].

Madej described four road-removal treatments used in the Redwood Creek watershed [1]. Some roads received no treatment; nothing was done to improve the road (Figure 1a). The second treatment, road upgrade, is often used for road reaches between the stream crossings, also called the "ripped and drained" treatment. In this method the road surface is decompacted and drains are constructed perpendicular to the road alignment, to dewater the inboard ditch (Figure 1b). Following treatment, the roads are mulched, seeded and replanted with native plant species.

The third treatment, minimum decompation, includes partially outsloping the road surface by excavating fill from the outboard edge of the road, and placing the material in the inboard ditch at the base of the cutbank (Figure 1c). A fourth treatment includes total outslope of the road bench, which involves covering the cutbank with excavated fill (Figure 1d). Original topsoil from the outboard edge of the road is replaced on the road bench where possible and the road benches are fully recontoured. Stream crossings with culverts were addressed with three treatment levels for this project. The first is no treatment where nothing is done to improve the crossing. The second treatment "CDF Style" treatment, includes removing the culvert, "pulling back" fill material, and stabilizing the stream banks. The third treatment is "full treatment", which includes excavating the crossing to the original stream channel and extensive recontouring of the banks [1].

Hillslope position is important for evaluating erosion [3]. Hillslopes were divided into three portions: upper,

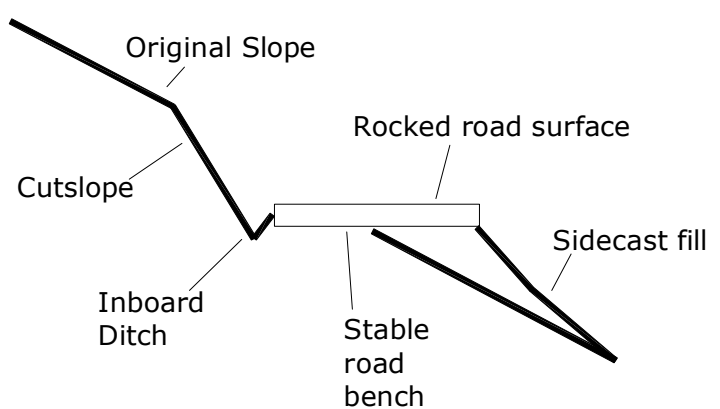

a Intact Road

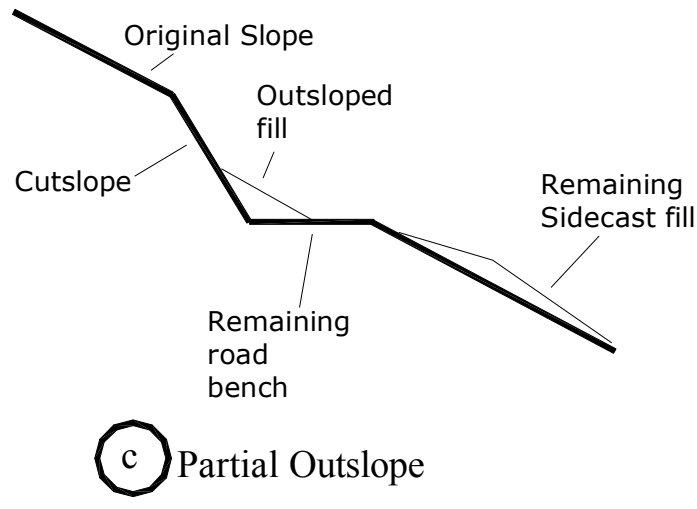

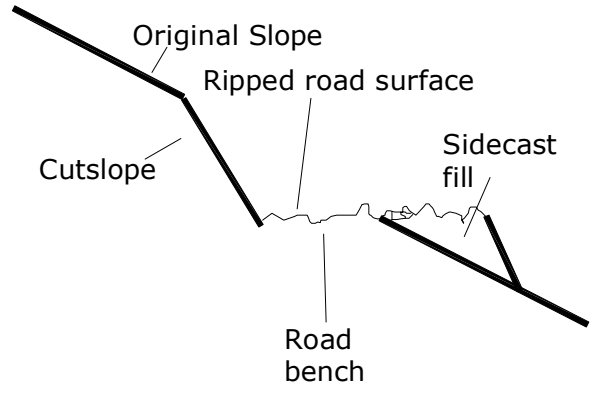

b Ripped and Drained

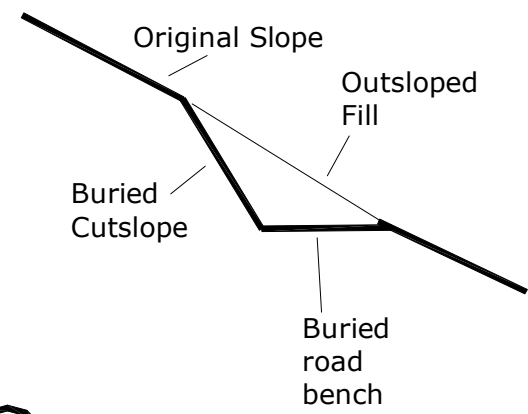

Total Outslope

Figure 1. Road Removal Treatments -drawn by Rebecca Teasley based on Madej [1]. 
mid-slope, and lower. This classification was based on the location of the road in relation to the distance from the adjacent ridgetop to the nearest major stream channel [1]. Roads closer to stream channels have a higher likelihood of contributing sediment to the stream.

Using quantitative field analysis, the researchers at Redwood National Park have estimated sediment saved values for the different treatment levels. Sediment saved is the sediment that would have been eroded and entered streams if a given level of treatment had not been completed.

\section{DYNAMIC PROGRAMMING}

Optimization models have not been applied to road removal management because until recently, effectiveness of saving sediment associated with varying road treatments was unknown. Optimization models circumvent the trial-and-error process, which identifies the optimal planning, design or control alternative [4]. A basic optimization model consists of the objective function that is either maximized or minimized by changing values of decision variables. The problem is subject to constraints and has bound constraints on the decision variables [5].

Developed in 1957 by Bellman, Dynamic Programming is an optimization algorithm that breaks a sequential or multistage decision process into a series of single stage optimization problems [4]. Optimization problems using DP are characterized by a set of input and output state variable vectors, decision variables, and a series of stages. Stages $(n)$ are the points in the problem where the decisions are made. Decision variables $\left(d_{n}\right)$ are the courses of action taken at each stage. State variables $\left(s_{n}\right)$ are the variables that describe the state of a system at any stage $\mathrm{n}$. Stage return $\left(r_{n}\right)$ is a scalar measure of the effectiveness of the decision making in each stage, stage return is a function of the input state, the output state, and the decision variables of any particular stage. Stage transformation or State transition $\left(t_{n}\right)$ is a function that expresses the relationships between the input state, the output state and the decisions [5]. The relationship between stages $(n)$, state variables $\left(s_{n}\right)$, decision variables $\left(d_{n}\right)$, stage return $\left(r_{n}\right)$, transformation function $\left(t_{n}\right)$ and the future value function will be discussed below in context of the road removal problem.

DP is solved via a backward recursive solution technique, which begins by finding the optimal decision for each possible state in the last stage $\left(f_{N}\right)$. The algorithm then advances from the last stage $(n=N)$ to the first stage $(n=1)$. One drawback of DP is the "Curse of Dimensionality" [6], which occurs when the number of recursive formula evaluations geometrically increases as the numbers of discretizations and/or state variables increase. These increases affect the amount of core memory and computation time required to solve a DP [5]. The computational time required to calculated a DP problem can be determined with the following equation:

$$
\text { CPU time } \propto(\# \text { stages }) *(\# \text { discrete decisions })^{n} *(\# \text { discrete states })^{m}
$$

where $n$ is the number of state variables and $m$ is the number of decision variables [6].

\section{MODEL DEVELOPMENT}

Values for sediment saved and cost for treatment data were obtained from the USGS [7]. Table 1 contains the sediment and cost data for roads based on their hillslope location and type of treatment. Figure 2 depicts the structure of the DP for the road removal management problem. The nodes represent states within the stages. The light lines between the states represent the possible or feasible decisions and associate with each line is a net benefit. The heavier line represents the optimal decision in the decision space. Road reaches are treated at four discrete levels of treatment where treatment levels were defined as the states in the DP model. Table 2 contains sediment savings and cost 


\begin{tabular}{|l|r|r|}
\hline $\begin{array}{c}\text { ROAllslope Location \& } \\
\text { Level of Treatment }\end{array}$ & $\begin{array}{c}\text { Sediment } \\
\text { Saved } \\
\left(\mathrm{yd}^{3} / \mathrm{mi}\right)\end{array}$ & $\begin{array}{c}\text { Cost/mile } \\
\text { of road }\end{array}$ \\
\hline Upper Slopes & 0 & $\$ 0$ \\
\hline No treatment & 250 & $\$ 5,280$ \\
\hline Road upgrade & 400 & $\$ 7,920$ \\
\hline Minimum decompaction & 490 & $\$ 15,840$ \\
\hline Total outslope & & \\
\hline & & \\
\hline Middle Slopes & 0 & $\$ 0$ \\
\hline \hline No treatment & 300 & $\$ 5,280$ \\
\hline Road upgrade & 650 & $\$ 7,920$ \\
\hline Minimum decompaction & 950 & $\$ 21,120$ \\
\hline Total outslope & & \\
\hline & & \\
\hline Lower Slopes & & \\
\hline \hline No treatment & 1000 & $\$ 6,600$ \\
\hline Road upgrade & 2000 & $\$ 7,920$ \\
\hline Minimum decompaction & 2500 & $\$ 26,400$ \\
\hline Total outslope & & \\
\hline
\end{tabular}

Table 1. Stream Crossing Sediment and Cost Data.

data for stream crossings. Stream crossings were discretized into three levels of treatment. Again, the treatment levels are defined as the states in the DP model.
From the sediment saved and cost data, the DP problem was developed based on a resource allocation problem by Mays and Tung [5], where the crossings and road reaches are the stages. Each stage has discrete states, which were levels of treatment. The objective of this model is to maximize the amount of sediment saved by selecting treatment of each road or crossing, subject to a budget.

$$
\operatorname{Max} Z=\sum_{n=1}^{N} r_{n}\left(s_{n}, d_{n}\right)
$$

subject to

$$
\sum_{n=1}^{N} c_{n} \leq B
$$

where: $s_{n}=$ the level of treatment for each road reach or crossing at each stage $(n) ; d_{n}$ $=$ the level of treatment for the next stage $n+1 ; r_{n}=$ the amount of sediment saved at each stage, $n$, as a function of crossing or road $\left(s_{n}\right)$ and treatment for the next stage $\left(d_{n}\right)$; and $c_{n}=$ the total cost of the project must be less than the budget $B$.

\section{Stages}

\section{Road $1 \quad$ Road $2 \quad$ Road 3}

\section{Crossing $1 \quad$ Crossing $2 \quad$ Crossing 3}
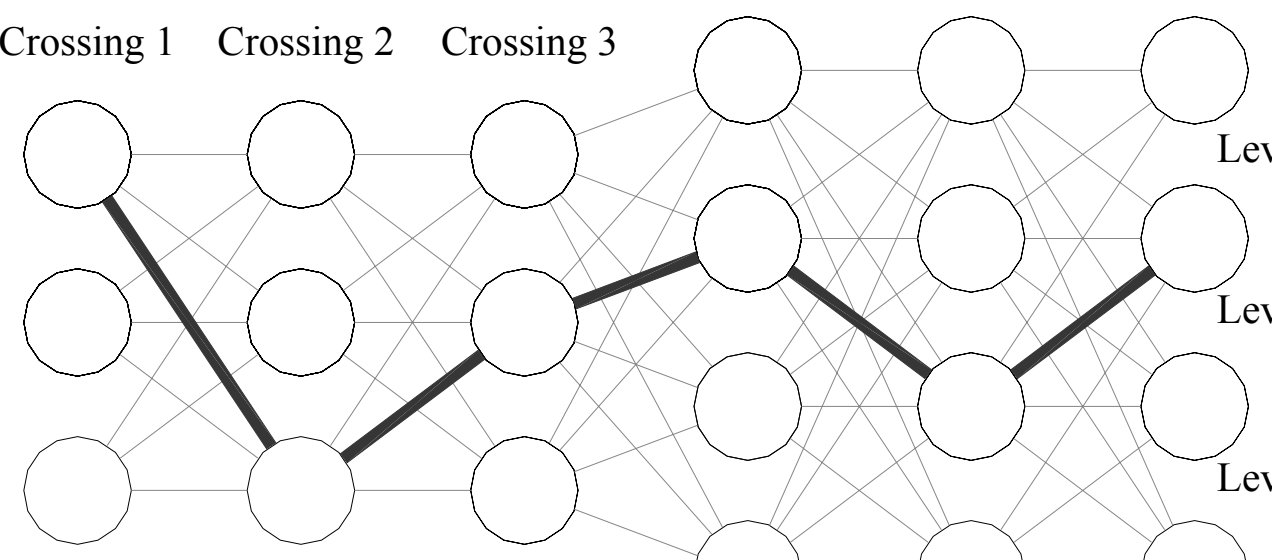

Level 1
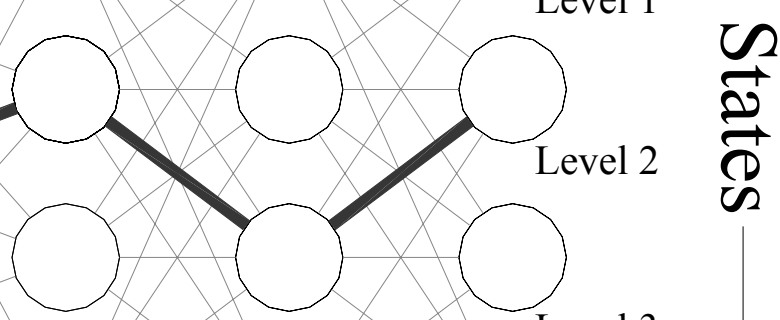

Level 3

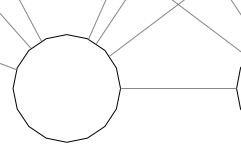

Level 4

Figure 2. Schematic of Road Removal Dynamic Program. 
To determine the optimal path through the stages, the recursive future value function is used.

$$
f_{n}=\max \left(r\left(s_{n}, d_{n}\right)+f_{n+1}\left(s_{n+1}\right)\right)
$$

The process begins at the end condition, when $\mathrm{N}$ is the final stage, is

$$
f_{N}\left(s_{N}\right)=\max \left(r_{N}\left(s_{N}, d_{N}\right)\right)
$$

The benefit obtained from the model is maximizing sediment saved. Based on the model, the DP optimization algorithm was programmed using Fortran 90 code.

\section{CRITERIA FOR A USEFUL DP MODEL}

The four main criteria for model usefulness as discussed with Dr. Mary Ann Madej of the USGS include: 1) ease of data input and output, 2) ability to handle basins of various sizes and varying budgets, 3) ability to determine treatment level for each road reach and stream crossing for optimal sediment savings, and 4) ease of interfacing with a Geographic Information System (GIS) model.

\section{RESULTS AND DISCUSSION}

\section{a. Calibration}

A calibration basin was developed with three crossings (one lower, one middle, and one upper) and three 20-mile reaches (one lower, one middle, and one upper). The results from the calibration basin were compared against the results of two other optimization approaches: Linear Programming (LP) and Genetic Algorithms (GA) (Table 3). The results of the LP and GA were developed by Mock and Simi, other students $[8,9]$. The LP spends more budget on treatment than the DP but the DP saves more sediment than the LP. The result shows that the DP solution is more optimal than the LP solution. The GA saved more sediment by using more of the budget than either the LP or the DP, indicating that the GA found a more optimal solution. This result indicated further research on the DP model was needed to discover the variation between the GA and the DP results.

\begin{tabular}{|l|r|r|}
\hline $\begin{array}{c}\text { CROSSINGS - } \\
\text { Hillslope Location \& } \\
\text { Level of Treatment }\end{array}$ & $\begin{array}{c}\text { Sediment } \\
\text { Saved } \\
\left(y d^{3}\right)\end{array}$ & $\begin{array}{c}\text { Cost/ } \\
\text { Crossing }\end{array}$ \\
\hline Upper Slopes & 0 & $\$ 0$ \\
\hline No treatment & 300 & $\$ 1,200$ \\
\hline CDF-style excavation & 400 & $\$ 2,100$ \\
\hline Full excavation & & \\
\hline Middle Slopes & 0 & $\$ 0$ \\
\hline No treatment & 600 & $\$ 2,400$ \\
\hline CDF-style excavation & 800 & $\$ 3,500$ \\
\hline Full excavation & & \\
\hline & & \\
\hline Lower Slopes & 0 & $\$ 0$ \\
\hline No treatment & 1000 & $\$ 3,600$ \\
\hline CDF-style excavation & 1200 & $\$ 5,250$ \\
\hline Full excavation & & \\
\hline
\end{tabular}

Table 2. Stream Crossing Sediment and Cost Data [7].

Simulations were completed with only the DP model for the calibration basin with budget set at $\$ 750,000$ but only $\$ 697,250$ was used and 66,400 cubic yards of sediment were saved (Table 4). The order of the reaches and crossings being treated in the test basin were changed leaving the budget the same. For this simulation the cost was $\$ 644,450$ and the amount of sediment saved was 66,200 per cubic yard. The second line in Table 4 shows that the same optimal decision was not reached as in the previous simulation.

\section{b. Cost/Benefit Analysis}

To explore variation in the results, cost/benefit ratios for each treatment level and location were calculated. The lower the

\begin{tabular}{|c|c|c|}
\hline $\begin{array}{c}\text { Optimization } \\
\text { Method }\end{array}$ & $\begin{array}{c}\text { Sediment } \\
\text { Saved }\left(y d^{3}\right)\end{array}$ & Total Cost \\
\hline $\begin{array}{c}\text { Linear } \\
\text { Programming }^{\mathrm{a}}\end{array}$ & 61,200 & $\$ 716,650$ \\
\hline $\begin{array}{c}\text { Genetic } \\
\text { Algorithms }\end{array}$ & 69,300 & $\$ 749,150$ \\
\hline $\begin{array}{c}\text { Dynamic } \\
\text { Programming }\end{array}$ & 66,400 & $\$ 697,250$ \\
\hline
\end{tabular}

Table 3. Calibration Basin Results for Three Optimization Models with Total Budget $\$ 750,000$. Sources: a) Mock (2001) [8] and b) Simi (2001) [9]. 


\begin{tabular}{|c|c|c|c|c|c|c|c|c|c|}
\hline \multirow{2}{*}{ Description } & \multicolumn{3}{c|}{ Roads Reaches } & \multicolumn{3}{c|}{ Stream Crossings } & \multicolumn{3}{c|}{ Summary of Results } \\
\cline { 2 - 10 } & Upper & Middle & Lower & Upper & Middle & Lower & Budget & $\begin{array}{c}\text { Cost of } \\
\text { Treatment }\end{array}$ & $\begin{array}{c}\text { Sediment } \\
\text { Save (yd3) }\end{array}$ \\
\hline $\begin{array}{c}\text { Calibration Basin- 3 } \\
\text { crossing, 3-20 mile } \\
\text { road reaches }\end{array}$ & $2 *$ & 4 & 3 & $3 * *$ & 3 & 3 & $\$ 750,000$ & $\$ 697,250$ & 66,400 \\
\hline $\begin{array}{c}\text { Calibration Basin- 3 } \\
\text { crossing, 3-20 mile } \\
\text { road reaches }\end{array}$ & 4 & 3 & 3 & 3 & 3 & 3 & $\$ 750,000$ & $\$ 644,450$ & 66,200 \\
\hline
\end{tabular}

Table 4. Optimization Results of Calibration Basin. Numbers $\left({ }^{*}\right)$ indicate treatment level: 1) no treatment, 2) minimum decompaction, 3) partial outslope, 4) complete recontouring; Numbers $\left({ }^{* *}\right)$ indicate treatment level: 1) no treatment, 2) partial outslope, 3) complete recontouring

cost/benefit ratio the more effective the treatment. For road reaches, the ratios indicated that the most benefit was derived from treating the lower slope reaches with minimum decompaction (Table 5). The ratios also revealed full treatment of the reaches provided the least amount of benefit for the cost. The ratios also indicate that treating lower slope road reaches to any level provides more benefit than treating upper and middle reaches.

\begin{tabular}{|l|r|}
\hline \multicolumn{1}{|c|}{$\begin{array}{c}\text { Rollslope Location \& } \\
\text { Level of Treatment }\end{array}$} & $\begin{array}{c}\text { cost / } \\
\text { benefit } \\
\text { ratio }\end{array}$ \\
\hline Upper Slopes & 0 \\
\hline \hline No treatment & 21.1 \\
\hline Road upgrade & 19.8 \\
\hline Minimum decompaction & 32.3 \\
\hline Total outslope & \\
\hline & \\
\hline Middle Slopes & 17.6 \\
\hline \hline No treatment & 12.2 \\
\hline Road upgrade & 22.2 \\
\hline Minimum decompaction & \\
\hline Total outslope & 0 \\
\hline & \\
\hline Lower Slopes & 6.6 \\
\hline \hline No treatment & 10.6 \\
\hline Road upgrade & \\
\hline Minimum decompaction & \\
\hline Total outslope & \\
\hline
\end{tabular}

Table 5. Road Reach Cost/Benefit Ratios.
The cost/benefit analysis was completed for crossings (Table 6). The cost/benefit ratios revealed that CDF-style excavation yielded the greatest benefit for all hillslope locations. Treating the lower slope crossings at this level provides the highest benefit of all crossing treatments. Also noted from this analysis is that treating crossings provides more benefit for the cost than treating road reaches.

\section{c. Sample Basin}

The next simulations were for a sample basin provided by Dr. Madej [7] that was comprised of 240 crossings and 60 miles of road. The 240 crossings contained 120 upper slope, 80 mid slope and 40 lower slope crossings. The 60 miles was comprised of 20 miles of upper slope, 20 miles of mid slope and 20 miles of lower slope road reaches. The basin was simulated using a $\$ 500,000$ budget (Table 7 ) and a $\$ 1,000,000$ budget (Table 8 ). The results in Table 7 show that the LP saves more sediment and uses more budget than the DP, however, the GA still saves more sediment within the budget than either the DP or the GA. Table 8 shows that LP goes over budget indicating that the optimization failed by not remaining within the constraints of the model. The results of the optimization runs for the DP show improved sediment savings numbers, however the budget was not utilized as extensively as expected. The overall cost of the treatment leaves a large surplus of money after simulation. The DP stays within the budget and saves more sediment than the LP, however, the GA does significantly better with sediment savings than either the LP or DP. 


\begin{tabular}{|l|r|}
\hline \multicolumn{1}{|c|}{$\begin{array}{c}\text { CROSSINGS - } \\
\text { Level of Treatment }\end{array}$} & $\begin{array}{c}\text { cost / } \\
\text { benefit } \\
\text { ratio }\end{array}$ \\
\hline Upper Slopes & 0 \\
\hline No treatment & 4 \\
\hline CDF-style excavation & 5.3 \\
\hline Full excavation & 0 \\
\hline & 4 \\
\hline Middle Slopes & 4.4 \\
\hline No treatment & \\
\hline CDF-style excavation & 0 \\
\hline Full excavation & 3.6 \\
\hline & 4.4 \\
\hline Lower Slopes & \\
\hline No treatment & \\
\hline CDF-style excavation & \\
\hline Full excavation & \\
\hline
\end{tabular}

Table 6. Stream Crossing Cost/Benefit Ratios

The results of the optimization runs, when compared to the GA results indicate that the global optimum is not being found. The DP should always find the global optimum. This discrepancy is probably due to the sensitivity of the formulation to the order or stages as shown in Table 4. Further exploration was completed and it was determined the formulation of DP presented in the text by Mays \& Tung (1992) is sensitive to the order of the stages. Another DP resource allocation formulation, found in the text by Hillier \& Lieberman (2000), should be insensitive to the order of the stages.

\section{CONCLUSIONS}

The Dynamic Programming, Linear Programming, and Genetic Algorithm results were presented to Dr. Madej and her colleagues at the USGS. After reviewing the optimization results, Dr. Madej has advised that further research should be conducted pursuing the DP and GA approaches. Dr. Madej indicated that the DP formulation will meet the USGS criteria for ability to expand and handle basins of varying sizes and budgets.

A recommendation to the USGS is to consider using a cost/benefit analysis in the existing GIS model. These values could help decision-makers without the use of optimization modeling.

Currently, further research is being conducted to improve the results of the DP using the approach outlined in Hillier and Lieberman [10]. The reformulated DP should find a global optimum. Additionally, an input/output interface for the Fortran 90 code is being developed with the USGS existing GIS model.

\begin{tabular}{|c|c|c|}
\hline $\begin{array}{c}\text { Optimization } \\
\text { Method }\end{array}$ & $\begin{array}{c}\text { Sediment } \\
\text { Saved }\left(y d^{3}\right)\end{array}$ & Cost \\
\hline $\begin{array}{c}\text { Linear } \\
\text { Programming }\end{array}$ & 102,000 & $\$ 497,900$ \\
\hline $\begin{array}{c}\text { Genetic } \\
\text { Algorithms }\end{array}$ & 121,750 & $\$ 500,000$ \\
\hline $\begin{array}{c}\text { Dynamic } \\
\text { Programming }\end{array}$ & 101,300 & $\$ 498,200$ \\
\hline
\end{tabular}

Table 7. Optimization Results of Sample Basin Simulations for Three Optimization Methods with Total Budget of $\$ 500,000$. Sources: a) Mock (2000) [8] and b) Simi (2001) [9].

\begin{tabular}{|c|c|c|}
\hline $\begin{array}{c}\text { Optimization } \\
\text { Method }\end{array}$ & $\begin{array}{c}\text { Sediment } \\
\text { Saved }\left(y d^{3}\right)\end{array}$ & Cost \\
\hline $\begin{array}{c}\text { Linear } \\
\text { Programming }\end{array}$ & 102,000 & $\$ 1,000,250$ \\
\hline $\begin{array}{c}\text { Genetic } \\
\text { Algorithms }\end{array}$ & 200,850 & $\$ 999,530$ \\
\hline $\begin{array}{c}\text { Dynamic } \\
\text { Programming }\end{array}$ & 145,900 & $\$ 996,140$ \\
\hline
\end{tabular}

Table 8. Optimization Results of Sample Basin Simulations for Three Optimization Methods with Total Budget of $\$ 1,000,000$. Sources: a) Mock (2000) [8] and b) Simi (2001) [9]. 


\section{ACKNOWLEDGEMENTS}

Thank you to Dr. Elizabeth A. Eschenbach and Sheri L. Woo for their useful and insightful comments on this work and Dr. Mary Ann Madej of the USGS for the project background. A special thanks to Beth for a chance to work on this project

\section{REFERENCES}

1. Madej, Mary Ann, "Erosion and Sediment Delivery Following Removal of Forest Roads," Earth Surface Processes and Landforms 26, 175-190 (2000).

2. Gucinski, Hermann Michael J. Furniss, Robert R. Ziemer and Martha $\mathrm{H}$. Brookes, Forest Roads: A Synthesis of Scientific Information. U.S. Department of Agriculture, Forest Service, Pacific Northwest Research Station. Portland, Oregon General Technical Report PNWGTR-509 (May 2001).

3. Bloom, Anna L, "An Assessment of Road Removal and Erosion Control Treatment Effectiveness: A Comparison of 1997 Storm Erosion Response between Treated and Untreated Roads in Redwood Creak Basin, Northwestern CA." MSc. Thesis, Humboldt State University, Arcata, California (1998).
4. Willis, Robert and Finney, Brad, Environmental Systems Engineering and Economics, (Robert Willis, Arcata, California, USA, 2000)

5. Mays, Larry and Tung, Yeou-Koung, Hydrosystems Engineering and Management, (McGraw-Hill Publishers, Boston Massachusetts, USA, 1992).

6. Yeh, William W.-G., "Reservoir Management and Operations Models: A State-of-the-Art Review." Water Resources Research, 21 (12), 17971818 (1985).

7. Madej, Mary Ann (Personal communication, 2001).

8. Mock, Neil, "Managing a Forest Road Removal Project using Linear Programming". Semester Project, Water Resources Planning \& Management. Humboldt State University, Arcata, California, USA, 2001).

9. Simi, Jay, "Managing a Forest Road Removal Project using Genetic Algorithms". Semester Project, Water Resources Planning \& Management. Humboldt State University, Arcata, California, USA, 2001).

10. Hillier, Frederick S. and Gerald J. Lieberman, Introduction to Operations Research (McGraw-Hill. Boston, Massachusetts, USA, 2000).

Humboldt is consistently cited as being in the "Top 10\%" of all U.S. colleges and universities for academic quality. More than 400 faculty teach our 7,500 students in the arts, humanities, social sciences and natural sciences. We offer more than 100 undergraduate, graduate and preprofessional programs. In the California State University system - and nationwide - Humboldt is especially noted for small class size, low student-faculty ratio, time-to-graduation, graduation rate and job placements for graduates. Because of our academic distinction and low cost, Humboldt is named a "Best Buy" and "Top Value" university. 